\title{
ADSORÇÃO DO CORANTE AMARANTO UTILIZANDO FILMES DE QUITOSANA MODIFICADOS COM BENTONITA
}

\author{
F. K. RODRIGUES, R. FRÖHLICH, T. R. MARTINS, E. H. TANABE e G. L. DOTTO \\ Universidade Federal de Santa Maria, Departamento de Engenharia Química \\ E-mail para contato: felipet_kr@hotmail.com; ren.frohlich@gmail.com; \\ thitiorthitao@hotmail.com; guilherme_dotto@yahoo.com.br
}

\begin{abstract}
RESUMO - Este estudo teve como objetivo avaliar a adsorção do corante vermelho amaranto em filmes de quitosana preparados com adição de argila bentonita. Os filmes foram preparados e caracterizados. $\mathrm{Na}$ adsorção, foram avaliados o efeito do $\mathrm{pH}$ (2-10), taxa de agitação (50-150 rpm) e tempo de contato (0-240 min). Os melhores resultados foram obtidos em $\mathrm{pH} 2$, com $150 \mathrm{rpm}$, onde os filmes apresentaram capacidade de adsorção de $224 \mathrm{mg} \mathrm{g}^{-1}$ em $240 \mathrm{~min}$ de operação.
\end{abstract}

\section{INTRODUÇÃO}

Nas últimas décadas, os problemas ambientais têm se tornado cada vez mais críticos e frequentes. Neste contexto, o setor têxtil apresenta destaque devido a seu grande parque industrial instalado no país, originando grandes volumes de efluentes coloridos, os quais, quando não corretamente tratados, podem causar sérios problemas de contaminação (Kunz et al., 2002). A grande diversidade e complexidade desses efluentes, aliadas a imposições da legislação que exigem tratamentos eficientes, tem levado ao desenvolvimento de novas tecnologias que buscam o melhor e mais adequado tratamento, considerando custos, tempo e eficiência (Trombini e Obara-doi, 2012). Uma dessas tecnologias é a adsorção, que apresenta vantagens no ponto de vista ambiental e econômico, uma vez que podem ser utilizados resíduos como adsorventes. A quitosana, biopolímero encontrado em invertebrados marinhos, pode ser utilizada como adsorvente para remoção de corantes (Sousa et al., 2012). Porém, a quitosana possui uma estrutura física frágil e quebradiça, o que restringe o seu potencial de aplicação. Uma maneira de minimizar esse problema, dando a quitosana maior resistência, é a preparação de filmes de quitosana adicionados de argila bentonita. Este trabalho teve como objetivo avaliar a adsorção de vermelho amaranto utilizando filmes de quitosana modificados com argila bentonita. $\mathrm{O}$ estudo foi focado na preparação e caracterização dos filmes e sua aplicação em ensaios de adsorção em diferentes pHs, taxas de agitação e tempo de contato.

\section{MATERIAL E MÉTODOS}

\subsection{Amostras e Reagentes}

As soluções de corante foram preparadas com o corante vermelho amaranto (Duas Rodas, Santa Catarina, Brasil) e água deionizada. A quitosana em pó utilizada foi obtida a partir de cascas de camarão, conforme os estudos de Weska et al. (2007), Dotto et al. (2011) e

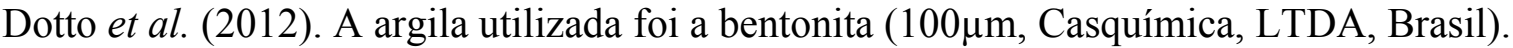




\subsection{Preparação e Caracterização dos Filmes de Quitosana com Bentonita}

Os filmes de quitosana com bentonita foram preparados a partir de uma solução de quitosana e uma dispersão de bentonita. A solução de quitosana foi preparada pela dissolução de $1,00 \mathrm{~g}$ de quitosana em $100 \mathrm{~mL}$ de uma solução a $1 \%(\mathrm{~m} / \mathrm{v})$ de ácido acético, sob agitação magnética (IKA-3622000) a $45^{\circ} \mathrm{C}$ durante 2 horas, com posterior filtração, ajuste de $\mathrm{pH}$ para 5 (utilizando uma solução $0,1 \mathrm{~mol} \mathrm{~L}^{-1} \mathrm{de} \mathrm{NaOH}$ ). A dispersão de bentonita/água deionizada foi preparada na concentração $1 \%(\mathrm{~m} / \mathrm{v})$ sob agitação magnética (IKA-3622000) a $60{ }^{\circ} \mathrm{C}$ durante 5 minutos. Após, a solução de quitosana foi adicionada à dispersão de bentonita na razão de 5:1, sob agitação mecânica $(1200 \mathrm{rpm})$ a $60^{\circ} \mathrm{C}$ durante 4 horas. Decorrido o tempo, a mistura de quitosana com bentonita foi vertida em placas petri $(50 \mathrm{~mL}$ em cada) de $10 \mathrm{~cm}$ de diâmetro, que foram acondicionadas em estufa a $50{ }^{\circ} \mathrm{C}$ durante 20 horas. Após, os filmes foram retirados das placas. Amostras dos filmes foram caracterizadas através de fotografias de celular (Samsung, GT-S7582L, 5MP), mapeamento de raios-x e microscopia eletrônica de varredura (Jeol, JSM-6610LV).

\subsection{Ensaios de Adsorção}

Os ensaios de adsorção foram efetuados em batelada. Para estudo do $\mathrm{pH}$, foram utilizados $50 \mathrm{~mL}$ de solução com $100 \mathrm{mg} \mathrm{L}^{-1}$ de amaranto. Os valores de $\mathrm{pH}$ foram variados de 2 a 10, os quais, foram corrigidos com $\mathrm{NaOH}$ e $\mathrm{HNO}_{3} 0,1 \mathrm{~mol} \mathrm{~L}^{-1}$. A massa de adsorvente foi $0,01 \mathrm{~g}$. Os ensaios foram realizados em agitador termostático (Marconi, MA 093, Brasil) com agitação constante de $100 \mathrm{rpm}$ a $25^{\circ} \mathrm{C}$ durante 6 horas. Para estudo da cinética, foi utilizado $1,0 \mathrm{~L}$ de solução com $100 \mathrm{mg} \mathrm{L}^{-1}$ de amaranto e massa de adsorvente de $0,2 \mathrm{~g}$. A solução de amaranto teve seu $\mathrm{pH}$ corrigido (conforme estudo do $\mathrm{pH}$ ). Foram selecionados três valores de agitação $(50,100$ e $150 \mathrm{rpm})$, e coletadas amostras em onze diferentes tempos (2, $6,10,15,20,30,40,60,90,120$ e 240 minutos). A concentração remanescente de amaranto na fase líquida foi determinada por espectrofotometria a $521 \mathrm{~nm}$ (Shimadzu, UV mini-1240). A capacidade de adsorção no tempo $\left(\mathrm{q}_{\mathrm{t}}\right)$ foi determinada pela Equação 1:

$$
q_{t}=\frac{\left(C_{0}-C_{t}\right)}{m} V
$$

onde, $\mathrm{C}_{0}$ é a concentração inicial de amaranto em solução $\left(\mathrm{mg} \mathrm{L}^{-1}\right), \mathrm{C}_{\mathrm{t}}$ é a concentração de amaranto em solução no tempo $\mathrm{t}\left(\mathrm{mg} \mathrm{L}^{-1}\right)$, $\mathrm{m}$ é a massa de adsorvente $(\mathrm{g})$ e $\mathrm{V}$ é o volume de solução (L).

\section{RESULTADOS E DISCUSSÕES}

\subsection{Caracterização dos filmes}

A Figura 1 apresenta a imagem do filme de quitosana com bentonita.

Figura 1 - Filme de quitosana com bentonita. 


XI Congresso Brasileiro de Engenharia
Química em Iniciação Científica
Unicamp - Campinas - SP
19 a 22 de julho de 2015

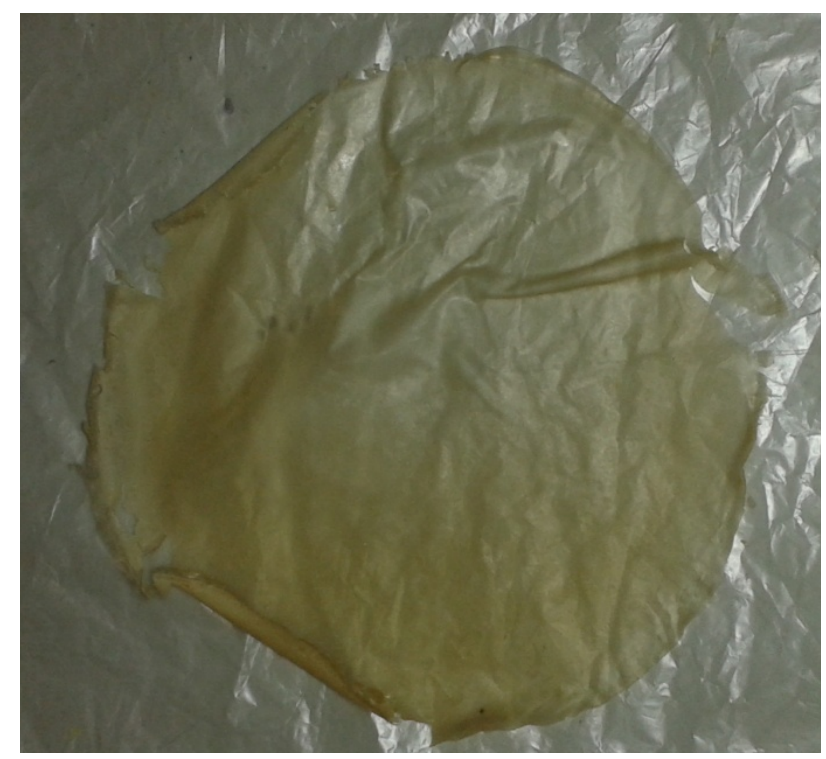

Pode ser verificado que o filme apresenta considerável resistência mecânica, uma vez que pode ser retirado facilmente das placas de petri, mantendo sua forma.

A Figura 2 apresenta as imagens de MEV do filme de quitosana com bentonita.

Figura 2 - MEV do filme de quitosana com bentonita, mostrando a quitosana (a) e a bentonita (b).

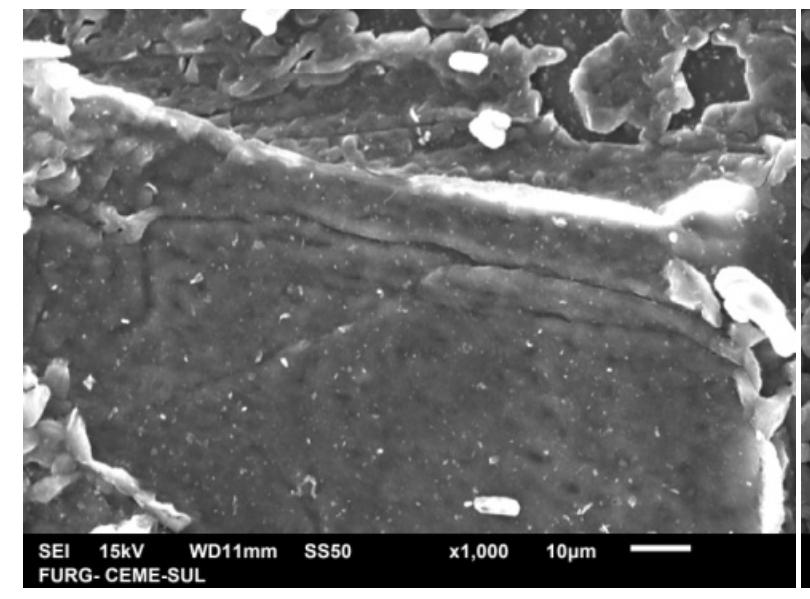

(a)

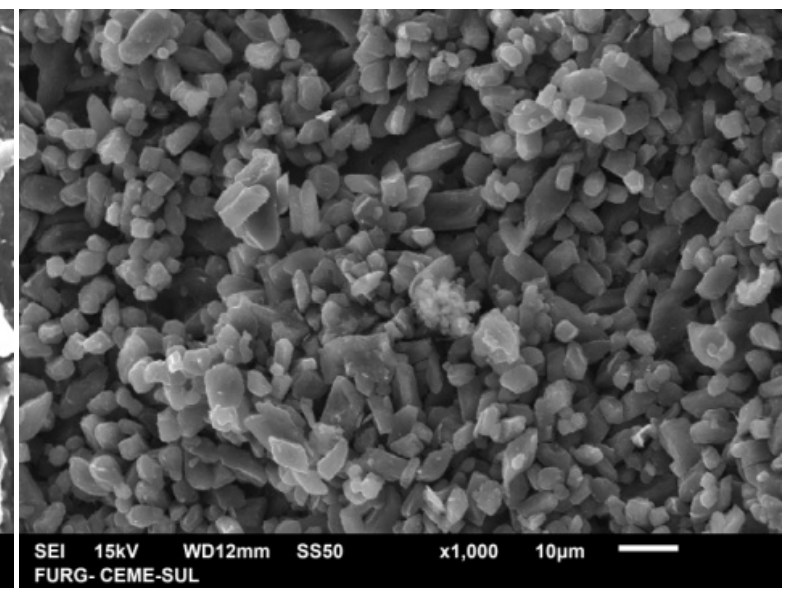

(b)

As imagens de MEV mostram que o filme apresentou características heterogêneas. Em alguns locais foi visualizada a quitosana (Figura 2a) e em outros, a argila bentonita (Fig. 2b).

A Figura 3 apresenta o mapeamento de raios $\mathrm{x}$ do filme de quitosana com bentonita, em termos de nitrogênio e silício.

Figura 3 - Mapeamento de raios $\mathrm{x}$ do filme de quitosana com bentonita, indicando o nitrogênio (a) e o silício (b). 


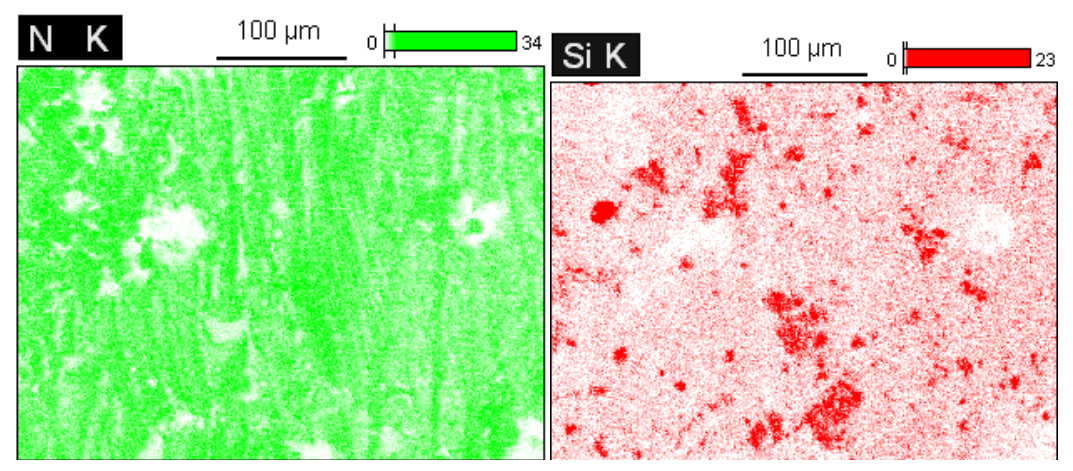

(a)

(b)

A Figura 3 mostra que apesar da estrutura heterogênea, o nitrogênio advindo da quitosana está presente por quase todo o filme apresentando poucas lacunas. O silício, proveniente da bentonita, também foi detectado ao longo de todo o filme, porém com uma incidência em alguns locais.

\subsection{Efeito do pH}

A Figura 4 apresenta o efeito do $\mathrm{pH}$ na adsorção de amaranto utilizando filmes de quitosana com bentonita.

Figura 4 - Capacidade de adsorção em função do pH da solução.

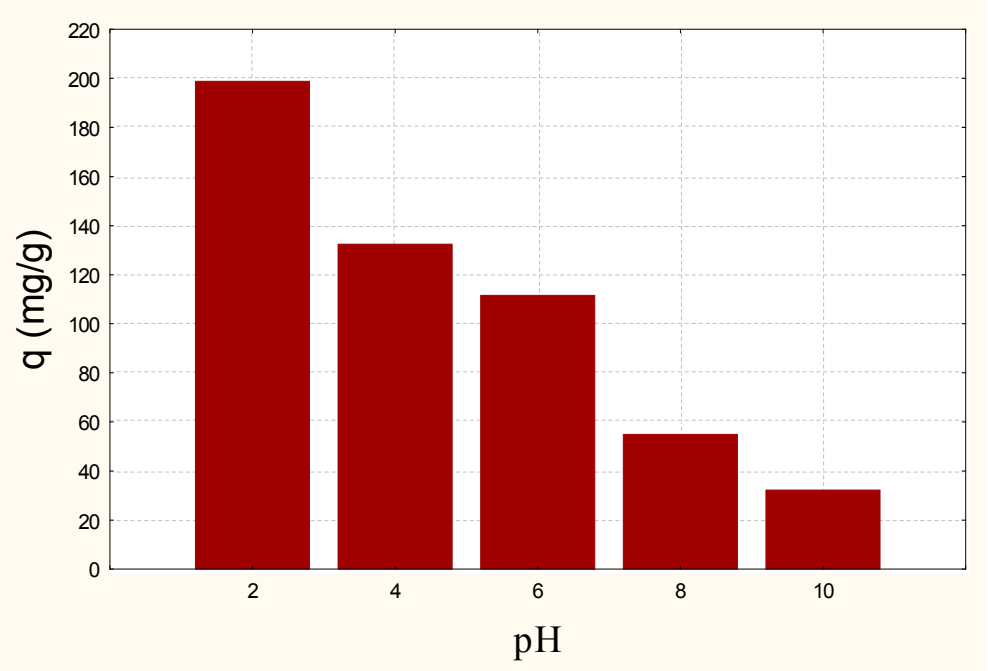

Pode ser verificado na Figura 4, que a capacidade de adsorção aumentou com a diminuição do $\mathrm{pH}$, alcançando valores próximos a $200 \mathrm{mg} \mathrm{g}^{-1}$. Isso se deve ao fato de que houve um aumento da quantidade de íons $\mathrm{H}^{+}$na superfície do adsorvente, ocorrendo assim a maior adesão das moléculas de corante vermelho amaranto (aniônicas) na superfície do filme. Outro fato importante observado foi que a estrutura do filme foi mantida mesmo em valores muito ácidos de $\mathrm{pH}$. Isto mostra que o $\mathrm{pH} 2$ foi o mais adequado para a adsorção do corante amaranto. 


\subsection{Estudo cinético}

A Figura 5 apresenta o estudo cinético na adsorção de amaranto utilizando filmes de quitosana com bentonita.

Figura 5 - Curvas da capacidade de adsorção em função do tempo

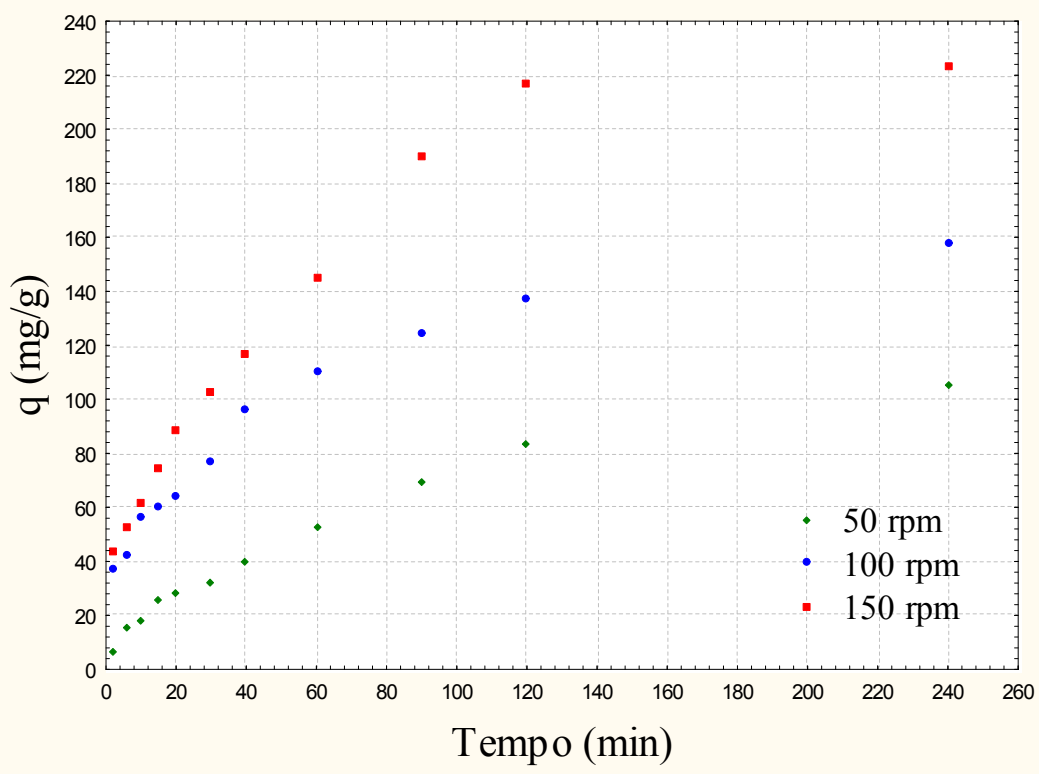

Na Figura 5 verifica-se que o aumento da taxa de agitação promoveu um aumento da capacidade de adsorção no tempo. Isso ocorreu devido ao aumento da dissipação de energia na zona de mistura do sistema, o que diminui a resistência externa e consequentemente facilita a transferência das moléculas do corante para a superfície do filme. Após 240 minutos de agitação, a capacidade de adsorção aumentou de $105 \mathrm{mg} \mathrm{g}^{-1}$ (50 rpm) para $224 \mathrm{mg} \mathrm{g}^{-1}$ (150 rpm). Isso mostra que a adsorção do corante amaranto foi favorecida a $150 \mathrm{rpm}$.

\section{CONCLUSÃO}

Neste trabalho foi estudada a adsorção do corante vermelho amaranto utilizando filmes de quitosana com bentonita. As principais conclusões foram: os filmes foram mais eficientes para a adsorção do corante em $\mathrm{pH} 2$, podendo-se inferir que o filme adquiriu cargas positivas já que o amaranto é um corante aniônico; mesmo em $\mathrm{pH}$ 2, a resistência do filme foi mantida; no decorrer do teste cinético a capacidade de adsorção aumentou substancialmente nas primeiras duas horas e após esse intervalo, a taxa de adsorção diminui consideravelmente; após 240 minutos, o aumento da taxa de agitação de 50 para $150 \mathrm{rpm}$ refletiu em um aumento de mais de $100 \%$ na capacidade de adsorção.

\section{REFERÊNCIAS}

DOTTO, G.L.; SOUZA, V.C.; PINTO, L. Drying of chitosan in a spouted bed: the influences of temperature and equipment geometry in powder quality, LWTFood Sci. Technol. v. 44, p. 1786-1792, 2011. 
DOTTO, G.L.; MOURA, J.M.; CADAVAL, T.R.S.; PINTO, L.A.A. Application of chitosan films for the removal of food dyes from aqueous solutions by adsorption, Chemical Engineering Journal. v. 214, p. 8-16, 2013.

KUNZ, A., PERALTA-ZAMORA, P.; MORAES, S.G. de; DURÁN, N. Novas tendências no tratamento de efluentes têxteis, Quím. Nova. v. 25, p. 78-82, 2002.

SOUSA, J.R. de; SILVA, A.B.S. da; SOUZA, L.F. de; SIGNINI, R. Avaliação da adsorção de cobre por quitosana e quitosana desacetilada, $52^{\circ}$ Congresso Brasileiro de Química, Recife, 2012.

TROMBINI, R.B.; OBARA-DOI, S. M. Remoção de cor e análises físico-químicas de efluentes de indústrias têxteis tratados com ganoderma spp, F@pciência, v. 9, p. 101$122,2012$.

WESKA, R.F.; MOURA, J.M.; BATISTA, L.M.; RIZZI, J.; PINTO, L.A.A. Optimization of deacetylation in the production of chitosan from shrimp wastes: use of response surface methodology, J. Food Eng. v. 80, p. 749-753, 2007. 